\title{
Luminescent Silica Nanobeads: Characterization and Evaluation as Efficient Cytoplasmatic Transporters for T-Iymphocytes
}

\author{
Massimo Bottini ${ }^{\star}, \dagger, \ddagger$, Fabio Cerignoli ${ }^{\dagger}$, David M. Mills ${ }^{\dagger}$, Federica D'Annibale ${ }^{\ddagger}$, Marilisa \\ Leone $^{\dagger}$, Nicola Rosato $\uparrow$, Andrea Magrini ${ }^{\ddagger}$, Maurizio Pellecchia ${ }^{\dagger}$, Antonio Bergamaschi $§$, and \\ Tomas Mustelin ${ }^{\dagger}$ \\ $\dagger$ Burnham Institute for Medical Research, 10901 North Torrey Pines Road, La Jolla, CA 92037, USA \\ $\$$ Department of Environmental, Occupational, and Social Medicine, University of Rome Tor Vergata, Via \\ Montpellier 1, 00133 Rome, Italy
}

II INFM and Department of Experimental Medicine and Biochemical Sciences, University of Rome Tor Vergata, Via Montpellier 1, 00133 Rome, Italy

§ Institute of Occupational Medicine, Università Cattolica del Sacro Cuore, Largo Agostino Gemelli 8, 00168 Rome, Italy

\begin{abstract}
We report the fabrication and characterization of neutravidin-conjugated silica nanobeads doped with a ruthenium-complex luminophore and functionalized with anti-human CD3 and anti-human CD28, and an acid-sensitive polymer. We observed that the nanobeads were readily delivered into Jurkat $\mathrm{T}$ leukemia cells by endocytosis, transported into lysosomes, and subsequently into the cytoplasm as revealed by $\mathrm{pH}$-sensitive luminescence. Since signs of cytotoxicity were not observed, the reported nanobeads could be an excellent and non-toxic building block for efficient intracellular transporters.
\end{abstract}

\section{Introduction}

The emerging field of nanomedicine, the use of the tools and knowledge of nanotechnology for biomedical purposes, is aimed at the preservation and improvement of human health and may lead to the development of more effective means for delivery and targeting of pharmaceutical, therapeutic, and diagnostic agents as compared to current methods. ${ }^{1}$ The development of nanotechnology-based agents involves the identification of precise targets (cell type and receptors) related to specific clinical conditions and of an appropriate nanocarrier to achieve the required responses while minimizing side effects. To enhance diagnostic or therapeutic efficacy, novel nanomaterials must have multivalent loading capacity for effective drug delivery, be engineered to function in biologically relevant environments, and facilitate detection. The transport of several types of engineered nanomaterials into adherent and nonadherent mammalian cell lines has been reported. ${ }^{2-8}$ Nevertheless, the chemistry of engineered nanomaterials has limited the efficient targeting of a specific cell line and their capacity to interact multivalently with cell membrane receptors. Furthermore, most complexes are internalized by endocytosis and not released into the cytoplasm but rather are trafficked rapidly from endosomes to lysosomes, the organelles that in the general endocytosis pathway enzymatically digest macromolecules and are characterized by a $\mathrm{pH}$ of approximately 4.5 . The lysosome barrier to cytoplasmic entry represents a significant challenge in the use of nanomaterials as intracellular delivery systems. Recently, $\mathrm{pH}$-sensitive polymers were

\footnotetext{
* Corresponding author. Phone: 858-646-3100 x3063; E-mail address: mbottini@ burnham.org.
} 
designed to be inactive at physiological $\mathrm{pH}$ and membrane active in the lower $\mathrm{pH}$ environment of developing endosomes. 9

Silica nanobeads (SNB) have been widely used for biosensing and catalytic applications due to their large surface area to volume ratio, straightforward manufacture, and capacity for doping and/or functionalization with fluorescent molecules, magnetic nanobeads or semiconducting nanocrystals. ${ }^{2,10-12}$ The present work focuses on an intracellular transporter constructed from neutravidin-conjugated SNB doped with a ruthenium-complex luminophore and functionalized with antibodies (anti-human CD3 and anti-human CD28) for T cell receptor (TCR) post-signaling endocytosis, and an acid-sensitive polymer for disruption of lysosomal compartments (Figure 1). The pH-dependent luminescence of the SNB permitted us to detect by flow cytometry whether the nanobeads were transported across the lysosomal membrane. Furthermore, the nanobeads were hydrophilic, biocompatible, and functionalizable with intracellularly active proteins and nucleic acids by exploiting the strong affinity between biotin and free neutravidin on the SNB surface. Therefore, the reported biomimetic nanoassemblies could be used to achieve a specific cytoplasmic effect in targeted cells.

\section{Experimental procedures}

\section{Materials}

Unless otherwise noted, reagent-grade chemicals were used without further purification. Deionized water was used for aqueous solutions. Cyclohexane, Triton X-100, n-hexanol, tetramethyl orthosilicate (TMOS), (3-aminopropyl)trimethoxysilane (APTS), (3-trihydroxy) silylpropyl methylphosphonate (THPMP), ammonium hydroxide ( $28 \% \mathrm{NH}_{3}$ in water), chlorotrimethylsilane (CTMS), tris(2,2'-bipyridine)dichlororuthenium(II) hexahydrate (Ru (bpy) 3 ), Annexin V-FITC, propidium iodide, poly---lysine, and formaldehyde were from Sigma-Aldrich (St. Louis, MO); amino-terminated poly(2-propylacrylic acid) (PPAA) was from Polymer Source, Inc. (Dorval, Canada); biotinylated anti-human CD3 and anti-human CD28 antibodies were from eBioscience, Inc. (San Diego, CA); normal mouse serum (NMS) from Santa Cruz Biotechnology (Santa Cruz, CA); normal goat serum (NGS) from Gibco (Invitrogen Corp., Carlsbad, CA); water-soluble biotin-labeling reagent sulfosuccinimidyl-6(biotin-amido)hexanoate (sulfo-NHS-LC-biotin), neutravidin (Nav) and Texas Redconjugated neutravidin (TRNav) from Pierce Biotechnology, Inc. (Rockford, IL); RPMI-1640 cell culture medium from Cellgro (Mediatech, Inc., Herndon, VA); fetal bovine serum (FBS) from Tissue Culture Biologicals (Informagen, Inc., Newington, NH); LysoTracker Green DND-26, FluoReporter biotin quantitation assay kit and FITC-labeled goat anti-rabbit antibody from Molecular Probes (Invitrogen Corp., Carlsbad, CA); PBS pH 7.4 (2.7 mM KCl, $1.5 \mathrm{mM}$ $\mathrm{KH}_{2} \mathrm{PO}_{4}, 137 \mathrm{mM} \mathrm{NaCl}$ and $8.1 \mathrm{mM} \mathrm{Na}_{2} \mathrm{HPO}_{4}$ ) from Mediatech, Inc. (Herndon, VA). Rabbit anti-human CD107A (LAMP-1) antibody was received from Prof. Minoru Fukuda's laboratory (Burnham Institute for Medical Research, La Jolla, CA). ${ }^{13}$

\section{Instrumentation}

Sonication and centrifugation were carried out using a Branson 3510 (Branson Ultrasonic Corporation, Danbury, CT) and a Centrifuge 5417R (Eppendorf AG, Hamburg, Germany), respectively. NMR spectra were collected at room temperature on a Bruker Avance-DRX 600$\mathrm{MHz}$ spectrometer equipped with a 5-mm probe and z-axis pulsed field gradients. Cell luminescence was assessed using a FACSCanto flow cytometer (channel FL1 for FITC, FL2 for (Ru(bpy) 3 or PI and FL5 for Texas Red) and FACSDiva software (BD Biosciences). Confocal microscopy (Radiance 2100/AGR-3Q, BioRad, Hercules, CA) was used to collect luminescent images after excitation at $457 \mathrm{~nm}$ or $488 \mathrm{~nm}$ using an argon laser. 60× (1.4-oil immersion) objective was used. Statistical analyses were realized using PRISM 4 for Windows (GraphPad Software, Inc., San Diego, CA). 


\section{Preparation of neutravidin-conjugated luminescent silica nanobeads}

A mixture of cyclohexane, Triton X-100, and n-hexanol (volume ratio 4.2:1:1; 24.8-mL final volume) was converted to a nanoemulsion by stirring at room temperature for $1 \mathrm{~h}$ before an aqueous solution of $\mathrm{Ru}(\mathrm{bpy})_{3}(940 \mu \mathrm{L})$ and TMOS $(100.5 \mu \mathrm{L})$ were added. The final concentration of $\mathrm{Ru}(\mathrm{bpy})_{3}$ in the reaction mixture was $1 \mathrm{mM}$. This mixture was sonicated for $1 \mathrm{~h}$ to facilitate the diffusion of TMOS into the encapsulated water droplets. A drop (59 $\mu \mathrm{L})$ of $28 \%$ aqueous $\mathrm{NH}_{4} \mathrm{OH}$ was added to catalyze the hydrolysis and condensation of TMOS. This mixture was stirred for $24 \mathrm{~h}$ before TMOS $(10.1 \mu \mathrm{L})$ was added, followed $30 \mathrm{~min}$ later by a mixture of APTS $(6 \mu \mathrm{L})$ and THPMP $(15.4 \mu \mathrm{L})$. After $12 \mathrm{~h}$ the hydroxyl groups on the surface of Ru(bpy) ${ }_{3}$-doped SNB (RuSNB) were capped by the addition of CTMS $(8.6 \mu \mathrm{L})$ followed by stirring for $12 \mathrm{~h}$. The RuSNB were precipitated with acetone $(25 \mathrm{~mL})$. The precipitated RuSNB (approximately $25 \mathrm{mg}$ ) were washed several times with water, then with anhydrous ethanol. A $1 \mathrm{mg}$ aliquot of RuSNB and $30 \mathrm{mg}$ of sulfo-NHS-LC-biotin were stirred for $2 \mathrm{~h}$ in phosphate-buffered saline (PBS, $2 \mathrm{~mL}$ ). Nav was kept at $37^{\circ} \mathrm{C}$ for $5 \mathrm{~min}$ and then centrifuged at $5000 \mathrm{~g}$ for $5 \mathrm{~min}$ to remove protein aggregates. The biotinylated nanobeads (RuSNB-biotin) were washed three times with PBS and then incubated with $5 \mathrm{mg}$ of Nav overnight at room temperature. The Nav-conjugated RuSNB (RuSNB-Nav) were washed with PBS until the absorbance of the wash at $280 \mathrm{~nm}$ demonstrated the absence of protein.

We produced control SNB decorated with Nav (SNB-Nav) or TRNav (SNB-TRNav) by following a protocol similar to that for the preparation of RuSNB-Nav by omitting the addition of $\mathrm{Ru}$ (bpy) 3 during the preparation of the SNB then incubating the biotinylated control SNB (SNB-biotin) with Nav or TRNav, respectively.

\section{Preparation of biotinylated poly (2-propylacrylic acid)}

PPAA (5 mg) and sulfo-NHS-LC-biotin ( $1 \mathrm{mg}$ ) were dissolved in DMF (50 $\mu \mathrm{L})$ and PBS (4 $\mathrm{mL}$ ), respectively. The two solutions were mixed and left to react at room temperature for $2 \mathrm{~h}$. To maximize the yield of biotinylated polymer (PPAA-biotin) another $1 \mathrm{mg}$ of sulfo-NHS-LCbiotin was added and left to react for $2 \mathrm{~h}$. PPAA-biotin was purified from unlinked sulfo-NHSLC-biotin by dialysis against PBS. The concentration PPAA-biotin (approximately $1 \mathrm{mg} / \mathrm{mL}$ ) was determined using a FluoReporter biotin quantitation kit.

\section{Functionalization of silica nanobeads with antibodies and the acid-sensitive polymer}

RuSNB-Nav (140 $\mu \mathrm{g}, 2.8 \times 10^{-11} \mathrm{~mol}$ of RuSNB) in $600 \mu \mathrm{L}$ of PBS were incubated with 30 $\mu \mathrm{g}$ of an equimolar mixture of anti-human CD3 and anti-human CD28 $\left(10^{-10}\right.$ moles of each antibody) (RuSNB-Nav- $\alpha_{3} \alpha_{28}$ ) for $1 \mathrm{~h}$, then $50 \mu \mathrm{L}$ of PPAA-biotin was added (RuSNB-Nav$\alpha_{3} \alpha_{28} \mathrm{p}$ ). After $1 \mathrm{~h}$ the RuSNB-Nav- $\alpha_{3} \alpha_{28} \mathrm{p}$ were washed 3 times in PBS.

\section{Flow cytometry}

Jurkat $\mathrm{T}$ leukemia cells (or Raji lymphoma B cells) were grown in RPMI-1640 supplemented with $10 \% \mathrm{FBS}$ at $37^{\circ} \mathrm{C}$ in $5 \% \mathrm{CO}_{2}$. Cells $\left(10^{5}\right)$ in logarithmic growth were washed with RPMI-1640, resuspended in $270 \mu \mathrm{L}$ of RPMI-1640, incubated with nanobeads (RuSNB-Nav, RuSNB-Nav- $\alpha_{3}$, RuSNB-Nav- $\alpha_{3} \alpha_{28}$, RuSNB-Nav- $\alpha_{3} \alpha_{28}$ p or SNB-TRNav- $\left.\alpha_{3} \alpha_{28}\right)(7 \mu \mathrm{g})$ in PBS $(30 \mu \mathrm{L})$ at $37^{\circ} \mathrm{C}$ in $5 \% \mathrm{CO}_{2}$, washed twice in PBS, and then resuspended in $1.5 \%$ formaldehyde in PBS $(200 \mu \mathrm{L})$.

\section{Cell toxicity}

Jurkat T leukemia cells were grown in RPMI-1640 supplemented with $10 \% \mathrm{FBS}$ at $37^{\circ} \mathrm{C}$ in $5 \% \mathrm{CO}_{2}$. Cells $\left(10^{5}\right)$ in logarithmic growth were washed with RPMI-1640, resuspended in 270 $\mu \mathrm{L}$ of RPMI-1640, and incubated with SNB-Nav- $\alpha_{3} \alpha_{28} \mathrm{p}(7 \mu \mathrm{g})$ in PBS $(30 \mu \mathrm{L})$ at $37^{\circ} \mathrm{C}$ in $5 \%$ $\mathrm{CO}_{2}$. Cells were washed twice with Annexin V (AV) buffer (10 mM HEPES/NaOH, pH 7.4, 
$140 \mathrm{mM} \mathrm{NaCl}, 2.5 \mathrm{mM} \mathrm{CaCl}_{2}$ ), resuspended in a solution of Annexin V-FITC, incubated at $4^{\circ} \mathrm{C}$ in the dark for $20 \mathrm{~min}$, washed, resuspended in a solution of propidium iodide (PI) and incubated at $4^{\circ} \mathrm{C}$ for $10 \mathrm{~min}$ before running the sample on the flow cytometer.

\section{Confocal microscopy}

Jurkat T leukemia cells were grown at $37^{\circ} \mathrm{C}$ in $5 \% \mathrm{CO}_{2}$ in RPMI- 1640 supplemented with $10 \%$ FBS at $37^{\circ} \mathrm{C}$ in $5 \% \mathrm{CO}_{2}$ atmosphere. Cells $\left(10^{5}\right)$ in logarithmic growth were washed with RPMI-1640, resuspended in $270 \mu \mathrm{L}$ of RPMI-1640, incubated with RuSNB-Nav- $\alpha_{3} \alpha_{28}$ or RuSNB-Nav- $\alpha_{3} \alpha_{28}$ p (7 $\left.\mu \mathrm{g}\right)$ in PBS $(30 \mu \mathrm{L})$ at $37{ }^{\circ} \mathrm{C}$ in $5 \% \mathrm{CO}_{2}$, then incubated for $30 \mathrm{~min}$ on poly-L-lysine-coated cover slips at $37^{\circ} \mathrm{C}$ in $5 \% \mathrm{CO}_{2}$ and then washed twice in PBS. The cells on the cover slips were fixed for $10 \mathrm{~min}$ in $3.7 \%$ formaldehyde in PBS, blocked and permeabilized with PBS containing 5\% NMS and 0.3\% Triton X-100. In order to visualize lysosomes, the cells were incubated with rabbit anti-CD107A in PBS containing 3\% NMS and $0.1 \%$ Triton X-100 and then stained with FITC-labeled goat anti-rabbit antibody in PBS containing $3 \%$ NGS and $0.1 \%$ Triton X-100. Alternatively, we visualized the lysosomes using a LysoTracker probe following the protocol of the supplier.

\section{Results and Discussion}

\subsection{Characterization of luminescent silica nanobeads decorated with neutravidin}

RuSNB were prepared in situ from Ru(bpy) ${ }_{3}$ using encapsulization in a water-in-oil nanoemulsion. Addition of organosilanes permitted the introduction of phosphonopropyl and 3 -aminopropyl groups onto the silica surface. The phosponate groups facilitated the dispersion of RuSNP in PBS and the subsequent biotinylation by coupling the surface amino groups to a biotin-labeling reagent followed by decoration with Nav.

Molecular weight estimation of RuSNB-Transmission electron microscope (TEM) images of RuSNB showed uniform diameter $(20 \pm 1 \mathrm{~nm})$ nanobeads (Figure 2). Assuming that the density of the SNB was equal to pure silica $\left(1.96 \mathrm{~g} / \mathrm{cm}^{3}\right)$ and the weight of encapsulated $\mathrm{Ru}(\mathrm{bpy})_{3}$ was negligible, the weight of one RuSNB having a 20-nm diameter was calculated $\left(1.96 \times 4 / 3 \pi \mathrm{r}^{3}\right)$ to be approximately $8.2 \times 10^{-18} \mathrm{~g}$ and, therefore, the molecular weight of a RuSNB was calculated (weight $\times$ Avogadro number) as approximately $5 \times 10^{6}$.

\section{Loading of luminophore molecules in RuSNB and biotin groups on RuSNB-}

biotin-We recorded the absorbance values at $452 \mathrm{~nm}$ of several concentrations of $\mathrm{Ru}$ (bpy) ${ }_{3}$ in PBS to obtain an extinction coefficient $\varepsilon_{\text {Rubpy }}(452 \mathrm{~nm})$ of approximately 12,500 $\mathrm{M}^{-1} \mathrm{~cm}^{-1}$. Subsequently, we subtracted the absorbance spectra of SNB dispersed in PBS from that of RuSNB dispersed in PBS to obtain the absorbance spectrum of Ru(bpy $)_{3}$ encapsulated in RuSNB. From the value of absorbance of encapsulated Ru(bpy $)_{3}$ at $452 \mathrm{~nm}$ and $\varepsilon_{\text {Rubpy }}(452 \mathrm{~nm})$ we estimated that approximately 300 molecules of Ru(bpy $)_{3}$ were encapsulated in each RuSNB.

The number of biotin groups on each RuSNB-biotin was determined using the FluoReporter biotin quantitation kit to be approximately $10^{4}$.

Loading of Nav on RuSNB-Nav-The presence of linked Nav on the surface of RuSNB$\mathrm{Nav}$ was determined on the basis of following observation. It has been reported that biotin binding blue-shifts the tryptophan luminescence emission peak $\left(\lambda_{\max }\right)$ and reduces the bandwidth at half height (full-width half-maximum, FWHM). ${ }^{14}$ Streptavidin and Nav are both tetrameric proteins carrying three tryptophans in each monomer. Upon excitation at $290 \mathrm{~nm}$ the RuSNB-Nav dispersion in PBS showed an emission band that was blue-shifted and narrower than that exhibited by free Nav dispersed in PBS (Figure 3A and Table 1). We 
prepared mixtures having molar ratios between Nav and biotin from 1:1 to 1:4. After $2 \mathrm{~h}$ of incubation we collected their emission spectra after excitation at $290 \mathrm{~nm}$. The tryptophan luminescence emission peak was observed to blue-shift and narrow with increasing biotin. In particular in the case of Nav:biotin molar ratio equal to 1:2 the emission spectrum resembled the one exhibited by RuSNB-Nav. Similar results were obtained with SNB-TRNav and free TRNav dispersed in PBS (Figure 3B and Table 2). The latter results suggest that each Nav (or TRNav) was linked to RuSNB-biotin (or SNB-biotin) through approximately 2 biotin molecules.

We recorded the absorbance values at $283 \mathrm{~nm}$ of several concentrations of Nav in PBS to obtain an extinction coefficient $\varepsilon_{\mathrm{Nav}}(283 \mathrm{~nm})$ of approximately $1.1 \times 10^{5} \mathrm{M}^{-1} \mathrm{~cm}^{-1}$. We subtracted the absorbance spectrum of RuSNB in PBS from the spectrum of RuSNB-Nav to obtain the spectrum of Nav linked to RuSNB. From the value of absorbance of Nav linked to RuSNB at $283 \mathrm{~nm}$ and $\varepsilon_{\mathrm{Nav}}(283 \mathrm{~nm})$ we calculated that approximately 40 proteins were on each RuSNBNav. A similar value was calculated for the number of TRNav on each SNB-TRNav.

Spectroscopic properties of RuSNB-Nav-Samples $(500 \mu \mathrm{L})$ used for NMR spectroscopy consisted of free $\mathrm{Ru}(\mathrm{bpy})_{3}(100 \mu \mathrm{M})$ and RuSNB-Nav (at a concentration such that encapsulated $\mathrm{Ru}(\mathrm{bpy})_{3}$ had a concentration of $100 \mu \mathrm{M}$ ) in PBS at $\mathrm{pH} 7.4$ containing $10 \%$ $\mathrm{D}_{2} \mathrm{O}$. The $\mathrm{pH}$ was changed by successive additions of concentrated $\mathrm{HCl}$. ${ }^{1} \mathrm{H} \mathrm{NMR}$ spectra were acquired with 4,096 data points, 1,024 scans and a relaxation delay of $1 \mathrm{~s}$; a $90^{\circ}$ pulse of $7 \mu \mathrm{s}$ was implemented. Water suppression was achieved by means of a WATERGATE pulse scheme. The NMR spectrum of Ru(bpy) 3 at pH 7.4 (Figure 4A, black curve) exhibited sharp signals from the bipyridyl protons. Encapsulation of $\mathrm{Ru}(\mathrm{bpy})_{3}$ into the silica network caused large broadening of all NMR resonances although no shift in the signal positions with respect to the free chelate in solution was detected (Figure 4B, black curve). This result suggests a strong electrostatic interaction between $\mathrm{Ru}(\mathrm{bpy})_{3}$ and the silica surface, which is negatively charged at physiological $\mathrm{pH}$, that would decrease the total correlation time of the molecule and a rapid transverse relaxation that is generally characteristic of large macromolecular structures.

The absorbance spectra of both free and encapsulated $\mathrm{Ru}(\mathrm{bpy})_{3}$ dissolved in PBS at $\mathrm{pH} 7.4$ were characterized by a narrow peak at approximately $290 \mathrm{~nm}$ and a broad plateau in the 400-480 nm range, which we attribute to a ligand-to-ligand $\pi \rightarrow \pi^{*}$ transition and a $\mathrm{d} \rightarrow \pi^{*}$ metalto-ligand charge-transfer transition, respectively. The peaks in the spectrum of the encapsulated $\mathrm{Ru}(\mathrm{bpy})_{3}$ in PBS were slightly red-shifted and broader compared to those of free Ru(bpy) 3 (Figure 5A). In steady state experiments, excitation of RuSNB-Nav in PBS at $452 \mathrm{~nm}$ produced an emission band that was enhanced, blue-shifted and slightly narrower compared to that of free $\mathrm{Ru}(\text { bpy })_{3}$ in PBS (Figure 5B). The emission spectra were collected after having matched absorptions at the $452 \mathrm{~nm}$ excitation wavelength of free and encapsulated $\mathrm{Ru}(\mathrm{bpy})_{3}$. These results suggest that after encapsulation into the silica network the luminophore underwent a change in the conformation and a decrease in mobility due to strong electrostatic interactions with the silica surface. The increase in intensity of the emission peak can be accounted for by the decrease in mobility. It has been reported that luminophore mobility facilitates rapid internal conversion and efficient relaxation of the excited-state via nonradiative pathways due to intersections of the ground and excited-state energy surfaces. 15,16 The blue-shift and the decrease of full-width half-maximum of the emission peak can be accounted for by solvent$\mathrm{Ru}(\mathrm{bpy})_{3}$ interactions. As previously reported, the solvent reorganization energy term $(\chi)$ may influence the excited-state decay of luminophores in aqueous medium and changes in $\chi$ may affect the emission band line width. ${ }^{17-19}$ The silica surface of the nanobead pores contains a regularly spaced pattern of oxygen atoms that could serve as hydrogen bond acceptors, promote ordered water structure, and vary the solvation sphere of the encapsulated luminophores, thereby explaining the observed changes in line width. 
The effects of changing solvent polarity 20,21 and $\mathrm{pH}^{22,23}$ on the photophysical properties of many homo- and heteroleptic complexes of $\mathrm{Ru}$ (II) and $\mathrm{Ru}$ (II) complex-modified amino acids have been widely investigated. In particular, it has been reported that protonation of the metalto-ligand charge-transfer excited states leads to a diminution of luminescence lifetime and intensity. We analyzed the photophysical properties of free $\mathrm{Ru}(\mathrm{bpy})_{3}$ and RuSNB-Nav in PBS at $\mathrm{pHs}$ ranging from the physiologic value of 7.4 to 4 . The NMR (Figure 4A), absorbance (data not shown), and emission (data not shown) spectra of free Ru(bpy) ${ }_{3}$ in PBS were not influenced by changes in $\mathrm{pH}$. Indeed, because $\mathrm{Ru}(\mathrm{bpy})_{3}$ does not have a basic nitrogen on its periphery, its ground and excited states are not capable of being protonated. The NMR line broadening of RuSNB-Nav was strongly and gradually attenuated with decreasing pH (Figure 4B). The absorbance spectrum of SNB-Nav increased with increases in $\mathrm{pH}$ (Figure 6A) probably as a consequence of an increase in the extinction coefficient of the silica network due to its protonation. The absorbance spectrum of RuSNB-Nav exhibited the following features as the pH decreased: (i) background increases as was observed for SNB-Nav; (ii) decrease in intensity of the narrow peak at approximately $290 \mathrm{~nm}$ (Figure 6B); (iii) decrease in intensity of the broad plateau in the 400-480 $\mathrm{nm}$ range with the two peaks being slightly blue-shifted and changing their relative intensity (Figure 6C). Upon excitation at $452 \mathrm{~nm}$, the emission peak at $591 \mathrm{~nm}$ linearly decreased in intensity (Figure 6D and E) without any significant change in the line width. The observed changes in photophysical properties of encapsulated $\mathrm{Ru}(\mathrm{bpy})_{3}$ could be explained by silica network protonation that reduced the strength of the electrostatic interactions between the metal complex and the matrix and, therefore, increased mobility of the encapsulated luminophore. Higher mobility leads to an increase of the number of collisional encounters between the luminophore and the protonated silica network to quench luminescence while changes in the solvation sphere of encapsulated $\mathrm{Ru}(\mathrm{bpy})_{3}$ are unlikely to explain the observed $\mathrm{pH}$-dependent luminescence quenching because no significant changes in the line width were observed.

\subsection{Cell internalization of luminescent silica nanobeads decorated with neutravidin}

We first determined the maximum number of antibodies that linked each RuSNB-Nav. RuSNB-Nav ( $4 \mu \mathrm{g}$, approximately $8 \times 10^{-13} \mathrm{~mol}$ of RuSNB, assuming a molecular weight of $5 \times 10^{6}$, decorated with approximately $3.2 \times 10^{-11}$ moles of Nav, assuming 40 proteins on each RuSNB-Nav) in $20 \mu \mathrm{L}$ of PBS were incubated with $6 \mu \mathrm{g}$ of an equimolar mixture of anti-human CD3 and anti-human CD28 ( $2 \times 10^{-11}$ moles of each antibody, assuming a molecular weight of $1.5 \times 10^{5}$ ) for $1 \mathrm{~h}$. The nanobeads were washed three times with PBS by centrifugation to give RuSNB-Nav- $\alpha_{3} \alpha_{28}$. We estimated the amount of antibody that bound the RuSNB-Nav by using polyacrylamide gel electrophoresis and Western immunoblotting. We observed that approximately $2.5-3.0 \mu \mathrm{g}\left(1.6-2 \times 10^{-11} \mathrm{~mol}\right)$ of total antibody was linked to the RuSNB-Nav while most the remaining 3.0-3.5 $\mu \mathrm{g}$ of total antibody was in the supernatant fraction collected after the first wash (Figure 7). This result suggests that the maximum number of antibodies that can be linked to a single RuSNB-Nav was between 20 and 25, which corresponds to approximately half of the Nav decorating the surface of the nanoparticle.

For cell internalization experiments RuSNB-Nav (140 $\mu \mathrm{g}, 2.8 \times 10^{-11} \mathrm{~mol}$ of RuSNB) were incubated with $30 \mu \mathrm{g}$ of an equimolar mixture of anti-human CD3 and anti-human CD28 $\left(10^{-10}\right.$ moles of each antibody). We verified the level of antibodies linked to the RuSNB-Nav using polyacrylamide gel electrophoresis and Western immunoblotting. The fact that the supernatant fraction collected after the first wash did not contain free antibodies suggested that all antibodies were linked to the Nav on the RuSNB-Nav and, therefore, that approximately 7 antibodies were available for each RuSNB-Nav- $\alpha_{3} \alpha_{28}$ (and RuSNB-Nav- $\alpha_{3} \alpha_{28}$ p).

RuSNB-Nav- $\alpha_{3} \alpha_{28}$ were readily internalized into Jurkat cells. The internal luminescence of cells treated with RuSNB-Nav- $\alpha_{3} \alpha_{28}$ was observed to significantly decrease within the first 3 
$h$ of incubation suggesting that in the first hours of incubation, RuSNB-Nav- $\alpha_{3} \alpha_{28}$ were continuously endocytosed by the cells, trafficked into the endosomes, and then rapidly to the lysosomes where their luminescence was quenched (Figure 8 and SI). As a control, we treated Jurkat cells with SNB decorated with Texas Red-conjugated Nav (SNB-TRNav), which were subsequently functionalized with anti-human CD3 and anti-human CD28 (SNB-TRNav$\alpha_{3} \alpha_{28}$ ). We observed a slight increase in cell luminescence over time (Figure 8 and SI), which was probably due to the continuous cellular uptake of nanobeads since SNB-TRNav dispersed in PBS did not show any variation in emission intensity with decreasing $\mathrm{pH}$.

The data suggest that binding of nanobeads to CD3 and CD28 was able to induce signaling through the TCR, and that signaling-induced endocytosis led to internalization of the antibodycovered nanobeads. TCR signaling induced by crosslinked anti-human CD3 with or without anti-human CD28 is followed by receptor internalization, which is a mechanism of signaling down regulation ("post-signaling endocytosis"). Microbeads are currently used as cross-linkers to induce TCR signaling. Our data suggest that nanobeads work as crosslinkers as well. Indeed T cells incubated for 1 hour with RuSNB-Nav- $\alpha_{3}$ or with RuSNB-Nav- $\alpha_{3} \alpha_{28}$ showed increased expression of CD69 (a marker of T cell activation) when compared to cells incubated with RuSNB-Nav (data not shown). Increased signaling following CD28 costimulation led to proportionally increased uptake of nanobeads through post-signaling endocytosis. Indeed lower uptake for anti-human CD3-conjugated RuSNB-Nav (RuSNB-Nav- $\alpha_{3}$ ) was observed to suggest that the costimulation of both CD3 and CD28 membrane receptors by RuSNB-Nav$\alpha_{3} \alpha_{28}$ increased the efficiency of the $\mathrm{T}$ cell receptor post-signaling endocytotic internalization (Figure 9). Internalization of nonconjugated RuSNB-Nav by Jurkat cells and of RuSNB-Nav$\alpha_{3} \alpha_{28}$ by Raji lymphoma B cells was very weak, suggesting that without stimulation of membrane receptors or in the absence of specific surface receptors endocytotic uptake of RuSNB-Nav was probably only due to non-specific interactions between the nanobeads and hydrophobic regions of the cell surface (Figure 9).

We next investigated the possibility of lysosomal release of RuSNB-Nav by measuring variations in internal cell luminescence. RuSNB-Nav- $\alpha_{3} \alpha_{28}$ were functionalized with a $\mathrm{pH}$ sensitive $\alpha$-propyl acrylic acid polymer (RuSNB-Nav- $\alpha_{3} \alpha_{28} p$ ). Jurkat T cells readily internalized RuSNB-Nav- $\alpha_{3} \alpha_{28} \mathrm{p}$ and exhibited an internal luminescence that was timeindependent, not statistically significant different from that of cells treated with RuSNB-Nav$\alpha_{3} \alpha_{28}$ after $1 \mathrm{~h}$ of incubation and higher than that of cells treated with RuSNB-Nav- $\alpha_{3} \alpha_{28}$ after 3 and $6 \mathrm{~h}$ of incubation (Figure 8 and SI). These results suggest that the polymer did not inhibit $\mathrm{T}$ cell receptor post-signaling endocytosis and enabled the release of the RuSNB-Nav- $\alpha_{3} \alpha_{28} \mathrm{p}$ from the lysosomes as soon as the nanobeads were transported into them.

Intracellular trafficking of RuSNB-Nav- $\alpha_{3} \alpha_{28}$ and RuSNB-Nav- $\alpha_{3} \alpha_{28} \mathrm{p}$ was investigated by confocal microscopy (Figure 10). RuSNB-Nav- $\alpha_{3} \alpha_{28}$ were readily internalized by cells and transported into lysosomal compartments (Figure 10, panels a, b and c) as shown by the yellow luminescence (images $\mathrm{C}$ and $\mathrm{D}$ ) corresponding to colocalization of lysosomes (green, image A) and intracellular nanobeads (red, image B). The luminescent features exhibited morphological changes with increasing incubation time. In particular, after $1 \mathrm{~h}$ incubation the cells mainly exhibited peripheral punctuate features (panel a). After $3 \mathrm{~h}$ of incubation less peripheral features were observed while more internal punctuate features appeared (panel $b$ ). After $6 \mathrm{~h}$ of incubation cells exhibited only a few intense luminescent features intracellularly. These results confirm the result obtained by flow cytometry that cells continuously internalized nanobeads primarily during the first $3 \mathrm{~h}$ of incubation. The peripheral features most likely correspond to endocytosed nanobeads just delivered into lysosomal compartments and, therefore, close to the cell membrane. Subsequently, the lysosomes encapsulating the nanobeads were trafficked intracellularly and finally fused to form a few large vescicles as revealed by their intense luminescent features after $6 \mathrm{~h}$ of incubation. 
RuSNB-Nav- $\alpha_{3} \alpha_{28}$ p were released from the lysosomes even after only $1 \mathrm{~h}$ of incubation (Figure 10 , panel d) suggesting that the polymer disrupted the lysosomal compartments as soon as the nanobeads were transported into them. After $3 \mathrm{~h}$ of incubation, nanobeads released from lysosomes were localized in a more internal part of the cell (Figure 10, panel e).

In the previous confocal evaluations lysosomes were visualized using an antibody specific for endosomal/lysosomal compartments (rabbit anti-CD107A) ${ }^{13}$ after having fixed and permeabilized the cells. Permeabilization of endosomal/lysosomal membranes could lead to leakage of the nanobeads from the vescicles and, therefore, compete with the acid-sensitive polymer. To confirm that the observed cytoplasmatic nanobeads were the result of the action of the polymer, we visualized the lysosomes using LysoTracker that was conjugated with a green luminophore which allowed us to perform the investigation without any previous membrane permeabilization. As showed in Figure 11, after $3 \mathrm{~h}$ of incubation with RuSNBNav- $\alpha_{3} \alpha_{28}$ p, the red luminescence of the nanobeads overlapped only partially with the green luminescence of lysosomes thereby confirming that the previously observed cytoplasmatic nanobeads were the result of to the disruption of the lysosomal compartments by the acidsensitive polymer and not due to internal leakage resulting from membrane permeabilization.

Cells incubated with RuSNB-Nav- $\alpha_{3} \alpha_{28} p$ showed intrinsic punctuate cytoplasmatic luminescence throughout the incubation time and independently of the technique used to visualize the lysosomes (Figure 10, panels d and e, and Figure 11). Punctuate (rather than diffuse) cytosolic luminescent features corresponding to nanoparticles that had escaped from lysosomes have been reported $2 \mathrm{a}, 6 \mathrm{a}$ and could be explained by a partial aggregation of nanoparticles during their permanence in the vesicles or, more likely, after their release into cytosol. However, the cause of this phenomenon is not clear at the moment and further investigation is warranted to understand the effect of surface functionality on cytoplasmic nanobead aggregation.

The reported results suggest that our nanobeads could be useful to achieve a specific cytoplasmatic effect in targeted cells. However, before developing any therapeutic applications, in vitro and in vivo, short- and long-term cytotoxic effects must be accurately established. Indeed, many nanomaterials (carbon nanotubes, 25 fullerenes, 26 quantum dots, 27 gold nanobeads, ${ }^{28}$ etc.) have shown signs of toxicity dependent upon such factors as dose, dimension, chemical functionalization, and physical aspect. Flow cytometry data showed that treatment with SNB-Nav- $\alpha_{3} \alpha_{28} \mathrm{p}$ did not induce any toxic effects on Jurkat T cells as compared to non-treated cells. Indeed, the number of apoptotic $\left(\mathrm{AV}^{+}\right)$and necrotic $\left(\mathrm{PI}^{+}\right)$cells was not significantly changed 1,3 , and $6 \mathrm{~h}$ after treatment with RuSNB-Nav- $\alpha_{3} \alpha_{28} \mathrm{p}$ and was not statistically different with respect to that of non-treated cells (control) (Figure 12 and SI).

\section{Conclusions}

In this article we report the fabrication and characterization of silica nanobeads doped with $\mathrm{Ru}$ (bpy) $)_{3}$, characterized by $\mathrm{pH}$-dependent luminescence and functionalized with anti-human CD3 and anti-human CD28, and with an acid-sensitive polymer. These nanoparticles were efficiently delivered into Jurkat $\mathrm{T}$ cells through $\mathrm{T}$ cell receptor post-signaling endocytosis, transported into lysosomal compartments, and subsequently to the cytoplasmatic region. Since signs of cytotoxicity were not observed, the reported nanobeads could be an excellent and nontoxic building block for efficient intracellular transporters.

\section{Supplementary Material}

Refer to Web version on PubMed Central for supplementary material. 


\section{Acknowledgements}

This work was supported by Grant U54 CA119335-02 from the National Institutes of Health and by PRIN grant No. 2006069554 from the Italian Ministry of University and Scientific Research. We thank Dr. Nunzio Bottini (University of Southern California, Los Angeles, CA), Dr. Ana Miletic Sedy (Burnham Institute for Medical Research, La Jolla, CA), and Mr. Matthew H. Cato (Burnham Institute for Medical Research, La Jolla, CA) for helpful comments.

\section{References}

1. (a) Moghimi SM, Hunter AC, Murray JC. FASEB J 2005;19:311. [PubMed: 15746175] (b) Salata O. J Nanobiotechnology 2004;2:3. [PubMed: 15119954] (c) Wagner V, Dullaart A, Bock AK, Zweck A. Nat Biotechnol 2006;24:1211. [PubMed: 17033654]

2. (a) Slowing I, Trewyn BG, Lin VSH. J Am Chem Soc 2006;128:14792. [PubMed: 17105274] (b) Lu CW, Hung Y, Hsiao JK, Yao M, Chung TH, Lin YS, Wu SH, Hsu SC, Liu HM, Mou CY, Yang CS, Huang DM, Chen YC. Nano Lett 2007;7:149. [PubMed: 17212455] (c) Kim JS, Yoon TJ, Yu KN, Noh MS, Woo M, Kim BG, Lee KH, Sohn BH, Park SB, Lee JK, Cho MH. J Vet Sci 2006;7:321. [PubMed: 17106221] (d) Chung TH, Wu SH, Yao M, Lu CW, Lin YS, Hung Y, Mou CY, Chen YC, Huang DM. Biomaterials. 2007ASAP (e) Xing X, He X, Peng J, Wang K, Tan W. J Nanosci Nanotechnol 2005;5:1688. [PubMed: 16245529] (f) Huang DM, Hung Y, Ko BS, Hsu SC, Chen WH, Chien CL, Tsai CP, Kuo CT, Kang JC, Yang CS, Mou CY, Chen YC. FASEB J 2005;19:2014. [PubMed: 16230334] (g) Lai CY, Trewyn BG, Jeftinija DM, Jeftinija K, Xu S, Jeftinija S, Lin VSY. J Am Chem Soc 2003;125:4451. [PubMed: 12683815] (h) Ravi Kumar MN, Sameti M, Mohapatra SS, Kong X, Lockey RF, Bakowsky U, Lindenblatt G, Schmidt H, Lehr CM. J Nanosci Nanotechnol 2004;4:876. [PubMed: 15570975]

3. (a) Bottini M, Cerignoli F, Dawson MI, Magrini A, Rosato N, Mustelin T. Biomacromolecules 2006;7:2259. [PubMed: 16903668] (b) Cai D, Mataraza JM, Qin ZH, Huang Z, Huang J, Chiles TC, Carnahan D, Kempa K, Ren Z. Nat Methods 2005;2:449. [PubMed: 15908924] (c) Kostarelos K, Lacerda L, Pastorin G, Wu W, Wieckowski S, Luangsivilay J, Godefroy S, Pantarotto D, Briand JP, Muller S, Prato M, Bianco A. Nature Nanotech 2007;2:108.

4. Shukla R, Bansal V, Chaudhary M, Basu A, Bhonde RR, Sastry M. Langmuir 2005;21:10644. [PubMed: 16262332]

5. Panyam J, Zhou WZ, Prabha S, Sahoo SK, Labhasetwar V. FASEB J 2002;16:1217. [PubMed: 12153989]

6. (a) Duan H, Nie S. J Am Chem Soc 2007;129:3333. [PubMed: 17319667] (b) Delehanty JB, Medintz IL, Pons T, Brunel FM, Dawson PE, Mattoussi H. Bioconjug Chem 2006;17:920. [PubMed: 16848398]

7. (a) Ito A, Shinkai M, Honda H, Kobayashi T. J Biosci Bioeng 2005;100:1. [PubMed: 16233845] (b) Corr SA, O'Byrne A, Gun'ko YK, Ghosh S, Brougham DF, Mitchell S, Volkov Y, Prina-Mello A. Chem Commun 2006:4474.

8. (a) Dinauer N, Balthasar S, Weber C, Kreuter J, Langer K, von Briesen H. Biomaterials 2005;26:5898. [PubMed: 15949555] (b) Ballthasar S, Michaelis K, Dinauer N, von Briesen H, Kreuter J, Langer K. Biomaterials 2005;26:2723. [PubMed: 15585276]

9. (a) Murthy N, Robichaud JR, Tirrell DA, Stayton PS, Hoffman AS. J Controlled Release 1999;61:137143. (b) Lackey CA, Press OW, Hoffman AS, Stayton PS. Bioconjugate Chem 2002;13:996.

10. (a) Tan W, Wang K, He X, Zhao XJ, Drake T, Wang L, Bagwe RP. Med Res Rev 2004;24:621. [PubMed: 15224383] (b) Bagwe RP, Yang C, Hilliard LR, Tan W. Langmuir 2004;20:8336-42. [PubMed: 15350111] (c) Bagwe RP, Hilliard LR, Tan W. Langmuir 2006;22:4357-4362. [PubMed: 16618187] (d) Santra S, Zhang P, Wang K, Tapec R, Tan W. Anal Chem 2001;73:4988. [PubMed: 11681477] (e) He X, Wang K, Tan W, Li J, Yang X, Huang S, Li D, Xiao D. J Nanosci Nanotech 2002;2:317. (f) Tapec R, Zhao XJ, Tan W. J Nanosci Nanotech 2002;2:405. (g) Yang HH, Qu HY, Lin P, Li SH, Ding MT, Xu JG. Analyst 2003;128:462. [PubMed: 12790198] (h) Yang W, Zhang CG, Qu HY, Yang HH, Xu JG. Anal Chim Acta 2004;503:163. (i) Ye Z, Tan M, Wang G, Yuan J. Anal Chem 2004;76:513. [PubMed: 14750841] (1) Wang L, Yang C, Tan W. Nano Lett 2005;5:37. [PubMed: 15792409]

11. (a) Yi DK, Selvan ST, Lee SS, Papaefthymiou GC, Kundaliya D, Ying JY. J Am Chem Soc 2005;127:4990. [PubMed: 15810812] (b) Yang HH, Zhang SQ, Chen XL, Zhuang ZX, Xu JG, Wang XR. Anal Chem 2004;76:1316. [PubMed: 14987087] 
12. (a) Rogach AL, Nagesha D, Ostrander JW, Giersig M, Kotov NA. Chem Mater 2000;12:2676. (b) Gerion D, Pinaud F, Williams SC, Parak WJ, Zanchet D, Weiss S, Alivisatos AP. J Phys Chem B 2001;105:8861. (c) Nann T, Mulvaney P. Angew Chem Int Ed 2004;43:5393.

13. Carlsson SR, Roth J, Piller F, Fukuda M. J Biol Chem 1988;263:18911. [PubMed: 3143719]

14. Kurzban GP, Gitlin G, Bayer EA, Wilchek M, Horowitz PM. J Protein Chem 1990;9:673. [PubMed: 2073320]

15. Webber NM, Litvinenko KL, Meech SR. J Phys Chem B 2001;105:8036.

16. Kummer AD, Kompa C, Niwa H, Hirano T, Kojima S, Michel-Beyerle ME. J Phys Chem B 2002;106:7554.

17. Cha X, Ariga K, Kunitake T. J Am Chem Soc 1996;118:9545.

18. Caspar JV, Meyer TJ. J Am Chem Soc 1983;105:5583.

19. Caspar JV, Sullivan BP, Kober EM, Meyer TJ. Chem Phys Lett 1982;91:91.

20. Sun H, Hoffman MZ. J Phys Chem 1993;97:11956.

21. Nair RB, Cullum BM, Murphy CJ. Inorg Chem 1997;36:962. [PubMed: 11669656]

22. Sun H, Hoffman MZ. J Phys Chem 1993;97:5014-5018.

23. Cargill Thompson AMW, Smailes MCC, Jeffery JC, Ward MD. J Chem Soc, Dalton Trans 1997:737743.

24. Alcover A, Alarcon B. Crit Rev Immunol 2000;20:325. [PubMed: 11100805]

25. Bottini M, Bruckner S, Nika K, Bottini N, Bellucci S, Magrini A, Bergamaschi A, Mustelin T. Toxicol Lett 2006;160:121. [PubMed: 16125885] (b) Sayes CM, Liang F, Hudson JL, Mendez J, Guo W, Beach JM, Moore VC, Doyle CD, West JL, Billups WE, Ausman KD, Colvin VL. Toxicol Lett 2006;161:135. [PubMed: 16229976] (c) Cui D, Tian F, Ozkan CS, Wang M, Gao H. Toxicol Lett 2005;155:73. [PubMed: 15585362] (d) Fiorito S, Serafino A, Andreola F, Togna A, Togna G. J Nanosci Nanotechnol 2006;6:591. [PubMed: 16573109]

26. Sayes CM, Gobin AM, Ausman KD, Mendez J, West JL, Colvin VL. Biomaterials 2005;26:7587. [PubMed: 16005959]

27. (a) Chang E, Thekkek N, Yu WW, Colvin VL, Drezek R. Small 2006;2:1412. [PubMed: 17192996] (b) Chan WH, Shiao NH, Lu PZ. Toxicol Lett 2006;167:191. [PubMed: 17049762] (c) Lovric J, Bazzi HS, Cuie Y, Fortin GR, Winnik FM, Maysinger D. J Mol Med 2005;83:377. [PubMed: 15688234]

28. Goodman CM, McCusker CD, Yilmaz T, Rotello VM. Bioconjugate Chem 2004;15:897. 

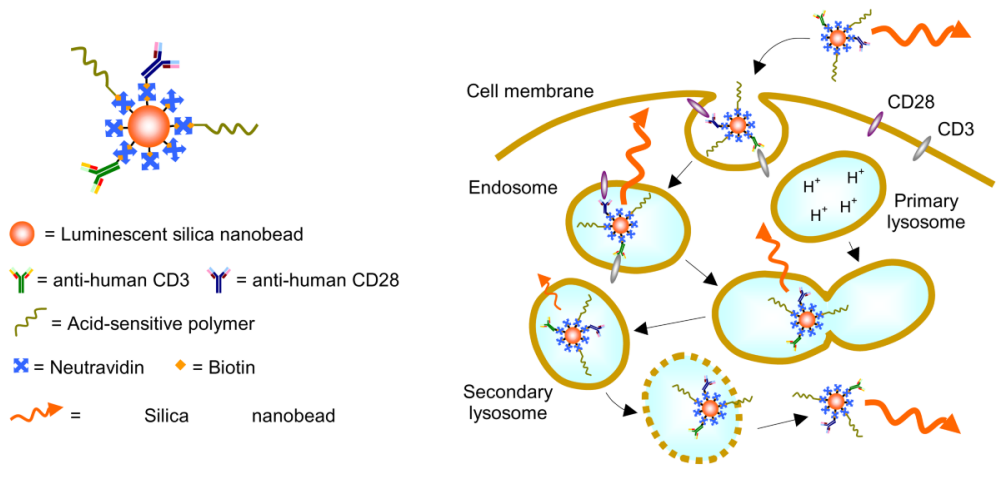

Figure 1.

Schematic of neutravidin-conjugated luminescent silica nanobeads functionalized with antibodies for $\mathrm{T}$ cell receptor post-signaling endocytosis and an acid-sensitive polymer for disruption of lysosomal compartments. The nanobeads were delivered into Jurkat T leukemia cells through endocytosis, transported into secondary lysosomes through the fusion of endocytotic vescicles with primary lysosomes, and subsequently into the cytoplasm as revealed by $\mathrm{pH}$-sensitive luminescence (the extent of which is indicated with orange arrows). 


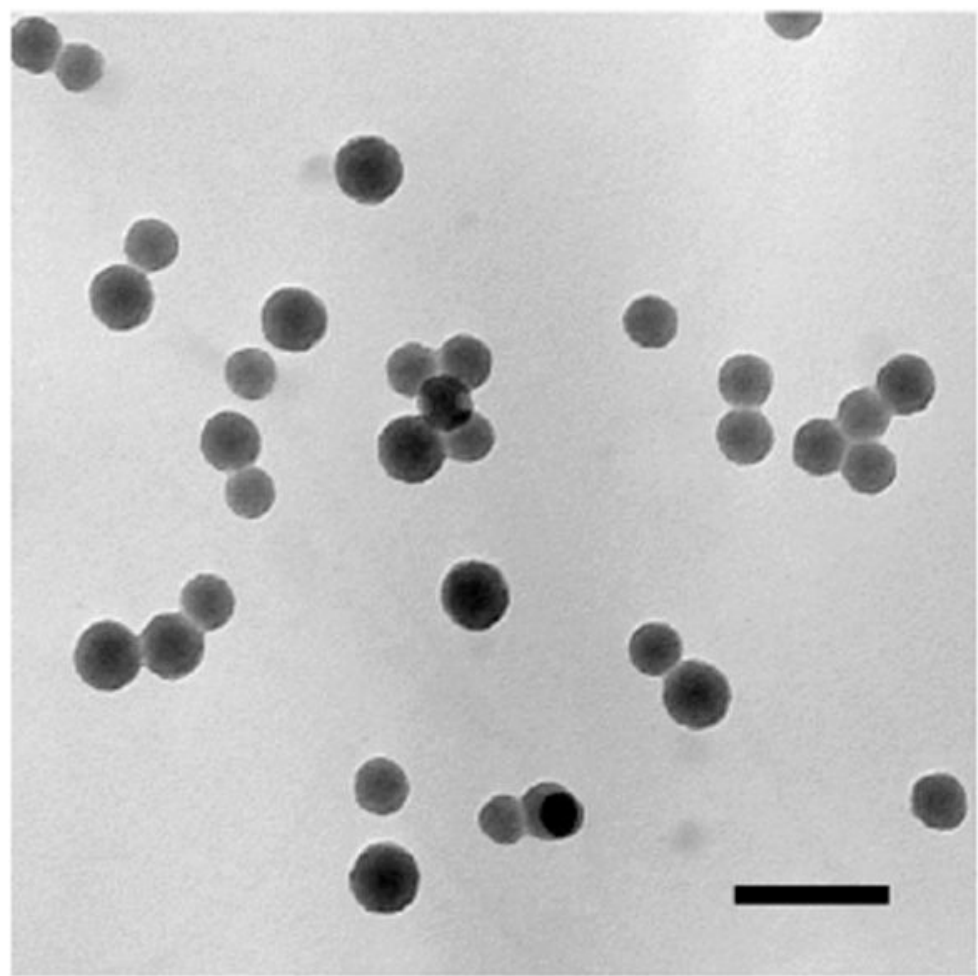

Figure 2.

TEM image of luminescent silica nanobeads. Scale bar $50 \mathrm{~nm}$. 

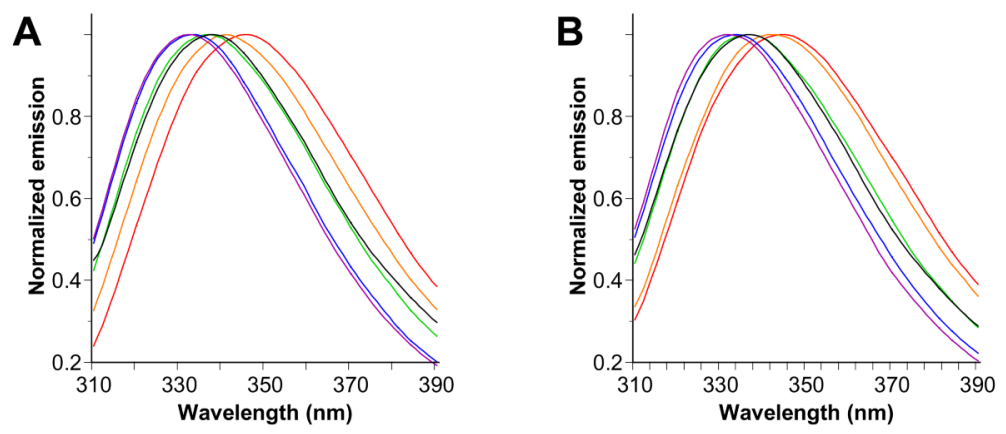

Figure 3.

Normalized emission spectra upon excitation at $290 \mathrm{~nm}$ for RuSNB-Nav (A) and SNB-TRNav (B) dispersed in PBS (black) and for mixtures in PBS of Nav (A) and TRNav (B) and biotin having molar ratios equal to 1:0 (red), 1:1 (orange), 1:2 (green), 1:3 (blue), and 1:4 (magenta). 

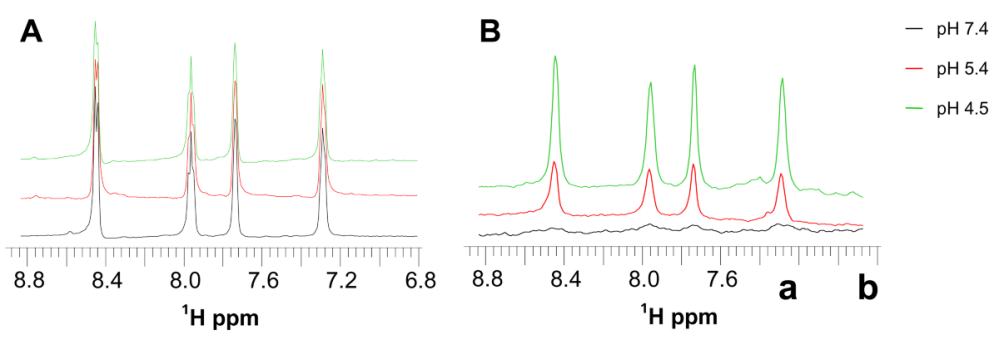

Figure 4.

NMR spectrum of free $\mathrm{Ru}(\mathrm{bpy})_{3}(\mathrm{~A})$ and RuSNB-Nav (B) in PBS at different $\mathrm{pH}$ values containing $10 \% \mathrm{D}_{2} \mathrm{O}$. 

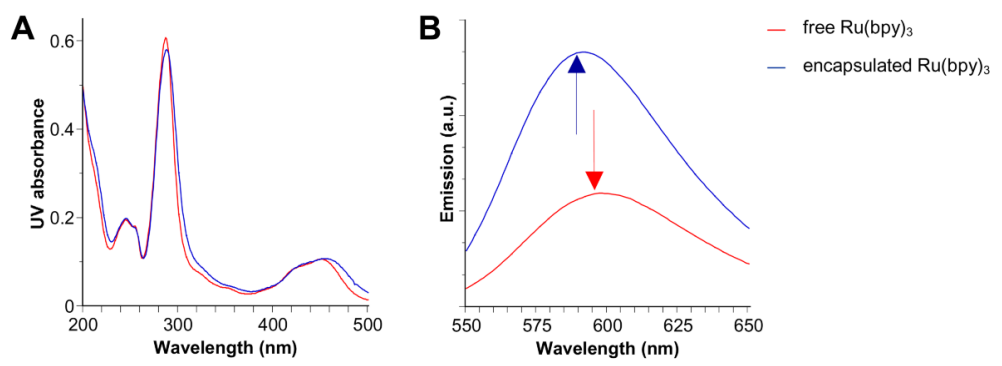

\section{Figure 5.}

(A) Absorbance spectra of free and encapsulated $\mathrm{Ru}(\mathrm{bpy})_{3}$ in $\mathrm{PBS}$ at $\mathrm{pH}$ 7.4. The absorbance spectrum of encapsulated $\mathrm{Ru}(\mathrm{bpy})_{3}$ was obtained by subtracting from the spectrum of RuSNBNav those of both SNB and Nav in PBS. (B) Emission spectra upon excitation at $452 \mathrm{~nm}$ of free and encapsulated $\mathrm{Ru}(\mathrm{bpy})_{3}$ in $\mathrm{PBS}$ at $\mathrm{pH}$ 7.4. Emission spectra were recorded after matching the absorbance values at $452 \mathrm{~nm}$ for free and encapsulated Ru(bpy $)_{3}$. Arrows indicate the emission peaks of encapsulated (blue arrow) and free (red arrow) $\mathrm{Ru}(\mathrm{bpy})_{3}$ in PBS at pH 7.4 . 

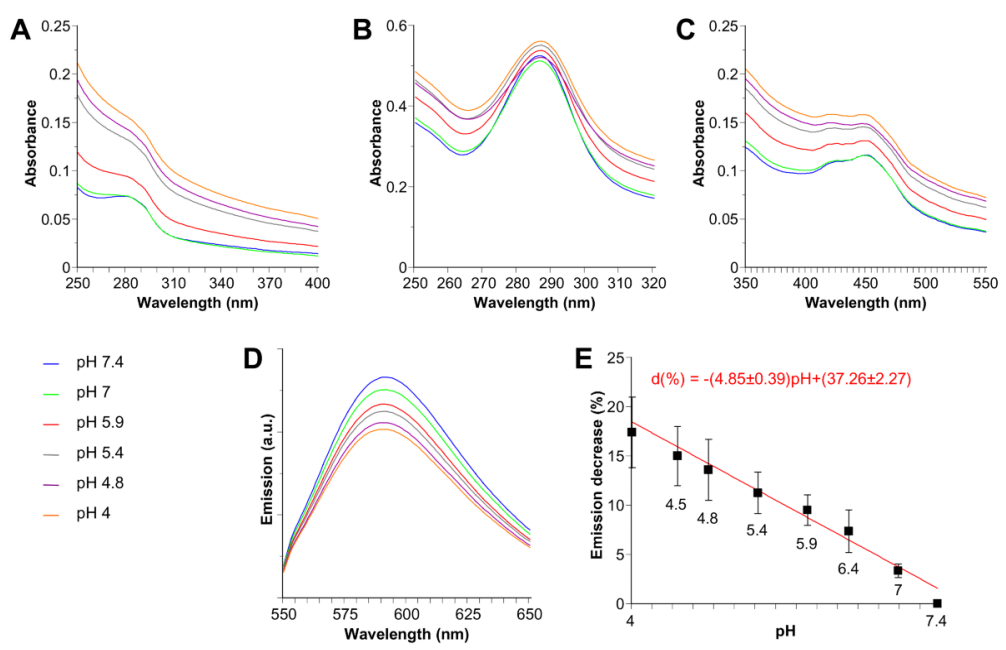

Figure 6.

(A) Absorbance spectra of SNB-Nav dispersed in PBS at pH values of 4 to 7.4. (B) Absorbance spectra in the UV range (corresponding to the ligand-to-ligand $\pi \rightarrow \pi^{*}$ transition) and (C) in the visible range (corresponding to the $\mathrm{d} \rightarrow \pi^{*}$ metal-to-ligand charge-transfer transition) of RuSNB-Nav dispersed in PBS at pH values of 4 to 7.4. (D) Emission spectra of RuSNB-Nav dispersed in PBS at $\mathrm{pH}$ values of 4 to 7.4. The absorbance and emission spectra were corrected by the corresponding concentration factors. (E) Decrease of RuSNB-Nav emission intensity with changing the $\mathrm{pH}$. Errors bars represent the standard deviations for triplicate experiments. 


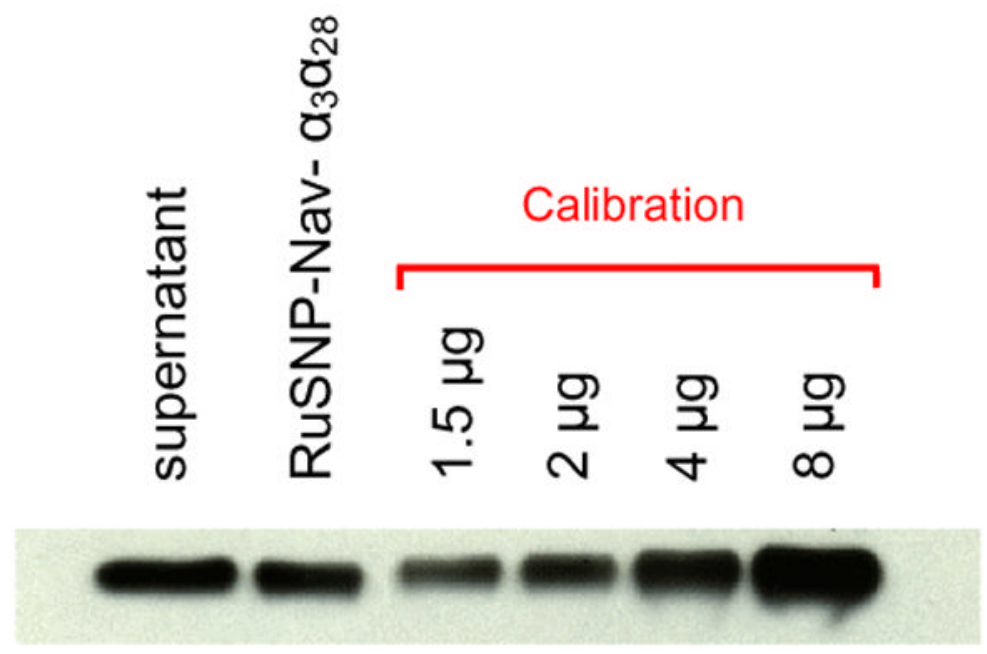

Figure 7.

Western blot analysis of the antibodies (anti-human CD3 and anti-human CD28) linked to 4 $\mu \mathrm{g}$ of RuSNB-Nav. RuSNB-Nav were incubated with $6 \mu \mathrm{g}$ of an equimolar mixture of antihuman CD3 and anti-human CD28 for $1 \mathrm{~h}$, then washed with centrifugation three times with PBS. Lanes 1 and 2 were the superrnatant fraction collected after the first wash and the pellet (RuSNB-Nav- $\alpha_{3} \alpha_{28}$ ) collected after the third wash, respectively. The other lanes contained different levels of equimolar anti-human CD3 and anti-human CD28 to obtain a loading curve. 

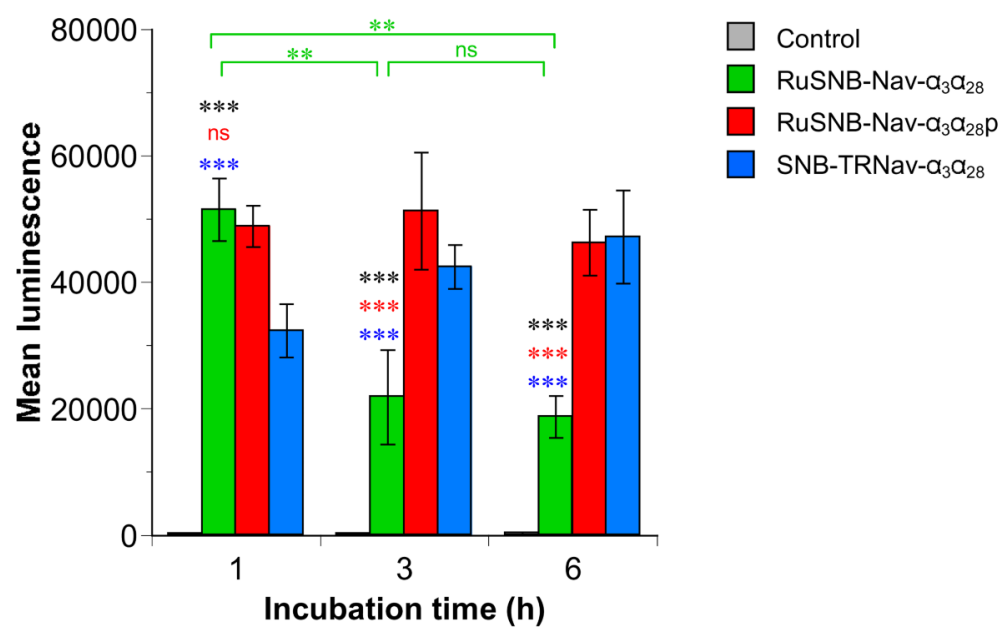

SNB-TRNav- $a_{3} a_{28}$

Figure 8.

Luminescence intensity dependence on the incubation time of Jurkat T leukemia cells with RuSNB-Nav- $\alpha_{3} \alpha_{28}$, RuSNB-Nav- $\alpha_{3} \alpha_{28}$ p, or SNB-TRNav- $\alpha_{3} \alpha_{28}$. Non-treated cells were used as control (grey). Statistical analysis: one-way analysis of variance (with Bonferroni's multiple comparison test) for RuSNB-Nav- $\alpha_{3} \alpha_{28}$ (green) and two-way ANOVA (with Bonferroni's post-test) for RuSNB-Nav- $\alpha_{3} \alpha_{28}$ vs. control (black), RuSNB-Nav- $\alpha_{3} \alpha_{28}$ p (red) and SNBTRNav- $\alpha_{3} \alpha_{28}$ (blue)); $\mathrm{ns}=P>0.05, *=P<0.05 ; * *=P<0.01 ; * * *=P<0.001$. Errors bars represent the standard deviation for triplicate experiments. 

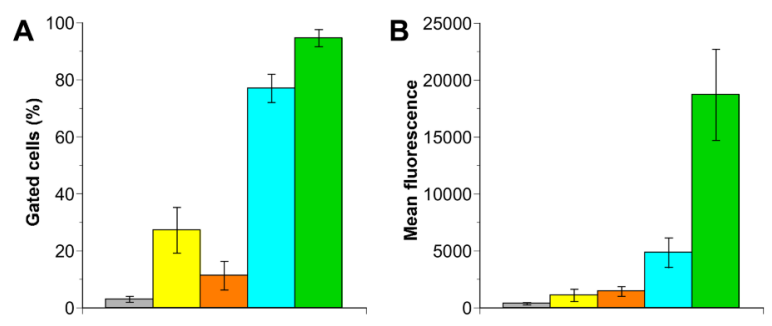

$\square$ Control

Jurkat + RuSNB-Nav

Raji + RuSNB-Nav- $a_{3} a_{28}$

$\square$ Jurkat + RuSNB-Nav-a a

$\square$ Jurkat + RuSNB-Nav- $a_{3} a_{28}$

Figure 9.

Efficiency (A) and luminescence intensity (B) of Jurkat T leukemia cells incubated for $6 \mathrm{~h}$ with RuSNB-Nav, RuSNB-Nav- $\alpha_{3}$ and RuSNB-Nav- $\alpha_{3} \alpha_{28}$ and of Raji lymphoma B cells incubated for $6 \mathrm{~h}$ with RuSNB-Nav- $\alpha_{3} \alpha_{28}$. Non-treated cells were used as control. Errors bars represent the standard deviation for triplicate experiments. 


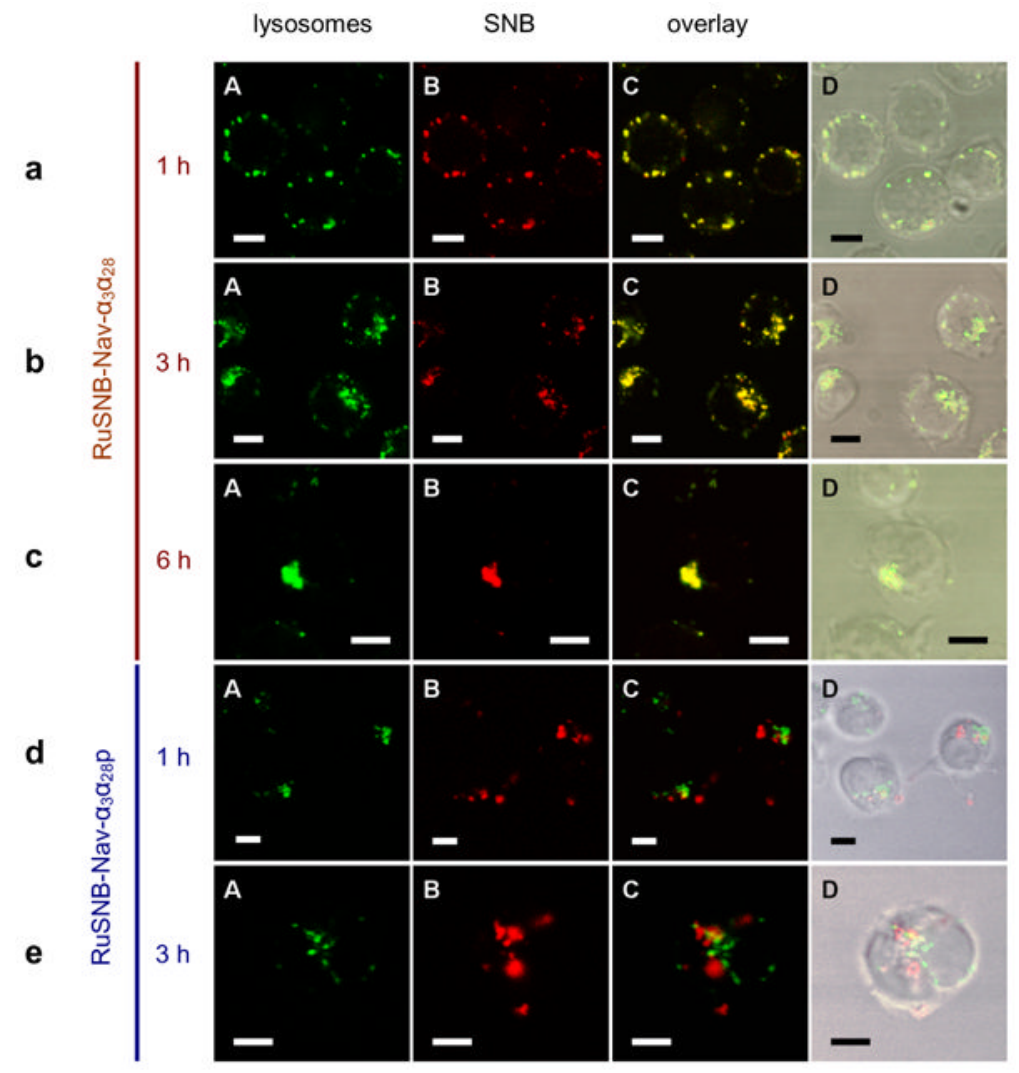

Figure 10.

Confocal images of Jurkat T leukemia cells incubated with RuSNB-Nav- $\alpha_{3} \alpha_{28}$ for 1 (panel a), 3 (panel b) and 6 (panel c) $h$ and with RuSNB-Nav- $\alpha_{3} \alpha_{28}$ p for 1 (panel d) and 3 (panel e) h. Images $\mathrm{A}$ and $\mathrm{B}$ showed lysosomal compartments and nanobeads, respectively. Image $\mathrm{C}$ is the superposition of $\mathrm{A}$ and $\mathrm{B}$. Image $\mathrm{D}$ is the superposition of $\mathrm{C}$ and the bright-field image of the cells. The cells were incubated with rabbit anti-CD107A and then with FITC-labeled goat antirabbit antibody in order to visualize lysosomes. Scale bars approximately $2.5 \mu \mathrm{m}$. 


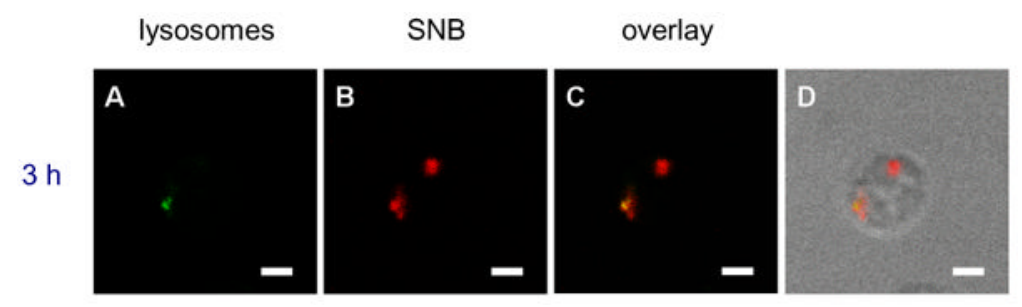

\section{Figure 11.}

Confocal images of Jurkat T leukemia cells incubated with RuSNB-Nav- $\alpha_{3} \alpha_{28} \mathrm{p}$ for $3 \mathrm{~h}$ and treated with LysoTracker to stain lysosomal compartments in order to avoid any membrane permeabilization. Images A and B showed lysosomal compartments and nanobeads, respectively. Image $\mathrm{C}$ is the superposition of $\mathrm{A}$ and $\mathrm{B}$. Image $\mathrm{D}$ is the superposition of $\mathrm{C}$ and the bright-field image of the cells. Scale bars approximately $2.5 \mu \mathrm{m}$. 

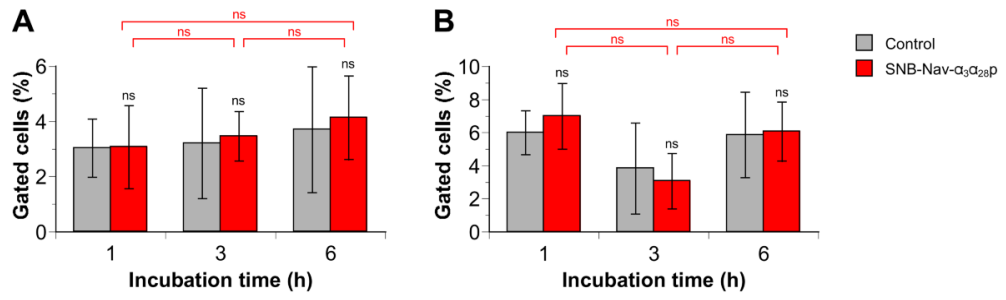

Figure 12.

Percentage of apoptotic (A) and necrotic (B) Jurkat leukemia T cells 1, 3, and $6 \mathrm{~h}$ after incubation with SNB-Nav- $\alpha_{3} \alpha_{28} \mathrm{p}$ (red) and treatment with Annexin V-FITC and PI to visualize apoptotic and necrotic cells, respectively. Non-treated cells were used as a control (grey). Statistical analysis: one-way analysis of variance (with Bonferroni's multiple comparison test) for SNB-Nav- $\alpha_{3} \alpha_{28}$ p (red) and two-way ANOVA (with Bonferroni's post-test) for SNB-Nav$\alpha_{3} \alpha_{28}$ p vs. control (black); ns $=P>0.05$. Errors bars represent the standard deviation for triplicate experiments. 
Table 1

Maximum emission wavelength and full-width half-maximum, for RuSNB-Nav dispersed in PBS and for mixtures with different molar ratios of Nav to biotin in PBS.

\begin{tabular}{ccc}
\hline Sample & $\lambda_{\max }^{\dagger}(\mathbf{n m})$ & FWHM $(\mathbf{n m})^{*}$ \\
\hline RuSNB-Nav & 338 & 61 \\
Nav:biotin $=1: 0$ & 346 & 63 \\
Nav:biotin $=1: 1$ & 341 & 61 \\
Nav:biotin $=1: 2$ & 337 & 59 \\
Nav:biotin $=1: 3$ & 333 & 55 \\
Nav:biotin $=1: 4$ & 332 & \\
\hline${ }^{\dagger}$ maximum emission wavelength, & & \\
${ }^{\ddagger}$ full-width half-maximum. & &
\end{tabular}


Table 2

Maximum emission wavelength and full-width half-maximum, for SNB-TRNav dispersed in PBS and for mixtures with different molar ratios of TRNav to biotin in PBS.

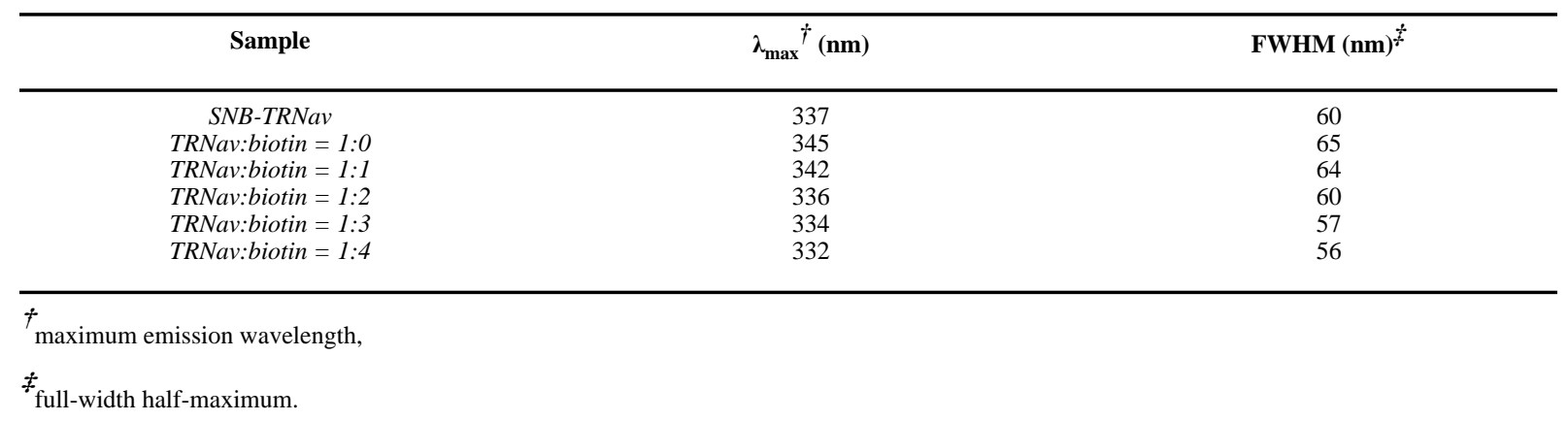


Table 3

Maximum emission wavelength and full-width half-maximum for free Ru(bpy) 3 and RuSNB-Nav in PBS at pH 7.4.

\begin{tabular}{|c|c|c|}
\hline Sample & $\lambda_{\max }^{\dagger}(\mathbf{n m})$ & FWHM $(\mathbf{n m})^{*}$ \\
\hline $\begin{array}{c}R u(b p y)_{3} \\
\text { RuSNB-Nav }\end{array}$ & $\begin{array}{l}598 \\
591\end{array}$ & $\begin{array}{l}72 \\
70\end{array}$ \\
\hline
\end{tabular}

